\section{Desenvolvimento Participativo de um Suporte para Almofada das Rendeiras de Bilro do Município de Saubara, Bahia}

\author{
Participatory Development of a Support Pillow for Bobbin \\ Lace Makers of the City of Saubara, Bahia
}

\section{RESUMO}

A economia solidária tem se apresentado como alternativa de geração de trabalho e renda que, na sua essência, se constitui de valores de cooperação, democracia e solidariedade. Na economia solidária há a preocupação com a inclusão social geradora de benefícios econômicos e melhores condições de saúde e trabalho. Baseado nesse pensamento, realizou-se a análise ergonômica do trabalho (AET) das rendeiras de bilro da Associação dos Artesãos de Saubara, cidade localizada no Recôncavo Baiano. Os resultados da AET das rendeiras de bilro revelaram condições posturais inadequadas, durante o rendar, aspecto que pode provocar lesões na coluna vertebral e nos membros superiores. A partir da análise desses dados, foi proposta a criação de um suporte para as almofadas, onde são confeccionadas as rendas, seguindo o método do design participativo. Espera-se que esse suporte possa melhorar a qualidade de vida das rendeiras de bilro de Saubara, Bahia, e que essta iniciativa possa ser replicada por rendeiras de em outras regiões do Brasil.

Palavras-chave: Economia solidária. Design participativo. Rendeiras.

\section{ABSTRACT}

The solidarity economy's has emerged as alternative source of employment and income, which in essence there are values of cooperation, democracy and solidarity. In solidarity economy's concern with social inclusion that generates economic benefits and improved health and work. Based on that thought there was the ergonomic analysis of work (EAW) of bobbin lace makers of the Association of Artisans Saubara, a city in Recôncavo Baiano. The results of EAW for bobbin lace makers proved inadequate postural conditions during the render, an aspect that can damage the spine and upper limbs. From the analysis of these data was proposed to create a support for the cushions, where rents are made by the method of participatory design. It is hoped that this support can
Gabriel Ribeiro

e Tatiana Ribeiro Velloso

Universidade Federal do Recôncavo da Bahia. Centro de Ciências Agrárias, Ambientais e Biológicas, Bahia, Brasil 
improve quality of life of bobbin lace makers of Saubara, Bahia and that this initiative can be replicated by the lace makers in other regions of Brazil.

Keywords: Solidarity economy's. Participatory design. Lace makers.

\section{INTRODUÇÃO}

A economia solidária surge como uma alternativa de organização capaz de gerar e de distribuir riquezas considerando que, para a reprodução de qualquer sociedade, são necessários os laços de solidariedade, de forma a contrapor o modelo individualista e competitivo [9]. Dessa forma, pode-se afirmar que a interação social dividiu-se em dois campos distintos na sociedade: o competitivo, vinculado ao processo de acumulação de capital, e o solidário, com a centralidade no ser humano.

A economia solidária (ES) compreende diferentes tipos de empreendimentos que objetivam proporcionar a seus membros benefícios econômicos. Esses empreendimentos surgem como reações a carências que o sistema dominante se nega a resolver, assim como uma forma de inverter o centro das atenções a partir do ser humano e não do capital [9].

Nesse contexto, os empreendimentos solidários possuem formas de organização como associações, cooperativas, empresas recuperadas autogestionárias, agricultura familiar, fundos rotativos solidários, redes e articulações de comercialização de cadeias produtivas solidárias. Segundo Roberto Silva e Maurício Faria [8], o "Brasil identificou, até agosto de 2007, a existência de quase 22 mil Empreendimentos Econômicos Solidários (EES), com cerca de um milhão e setecentos mil homens e mulheres”. Dentre as atividades dos EES, pode-se destacar o artesanato desenvolvido por rendeiras de bilro em diversas regiões do Brasil.

A renda de bilro é uma arte produzida a partir de cruzamentos e entrelaçamento de linhas, por meio de bilros (hastes cilíndricas de madeira) que são manejados sobre um esboço feito no papel. Este esboço de papel é fixado em uma almofada, através de alfinetes, que orientam a passagem dos fios dos bilros. As almofadas são apoiadas sobre um suporte (caixote) de madeira que é sobreposto em um banco ou cadeira, posicionado à frente do local onde as artesãs ficam sentadas [5].

Tal prática demanda alta repetição e grande velocidade nos movimentos de braços, punhos, mãos e dedos, movimentos esses que normalmente levariam ao desenvolvimento de lesões ocupacionais, tais como LER/DORT (Lesões por Esforços Repetitivos e Distúrbios Osteomusculares Relacionados ao Trabalho) que são lesões que ocorrem em ligamentos, músculos, tendões e em outros segmentos corporais, relacionadas à repetição de movimentos, posturas inadequadas e outros fatores, como a força excessiva.

Apesar disso, existe uma baixa prevalência de LER/DORT nas rendeiras de bilro por conta de fatores como: controle do próprio ritmo e jornada de trabalho; substituição do medo de demissão devido à insuficiência de produção pelo compromisso com o trabalho acabado; ausência de hierarquia, que minimiza o estado de tensão e alerta. Ainda assim, foram relatadas dores, parestesias em membros superiores e patologias como bursite e tendinite, que não foram relacionadas à atividade de rendar propriamente dita, mas às condições de trabalho inadequadas em que a mesma é desempenhada [5]. 
Frente a essa problemática, surge a possibilidade de intervenções no ambiente de trabalho, através de modificações no espaço físico no intuito de diminuir a sobrecarga musculoesquelética das trabalhadoras a partir do processo de incubação de empreendimentos solidários. $\mathrm{O}$ processo de incubação é inovador, porque tem a universidade como um dos sujeitos que pode contribuir e ter contribuição no sentido de promover a extensão universitária de forma integrada com o ensino e a pesquisa.

As incubadoras universitárias de empreendimentos solidários buscam atender às demandas tanto dos trabalhadores como de outros segmentos da economia solidária que possam apoiar a formação de empreendimentos solidários. Neste sentido, o objetivo deste trabalho foi descrever o processo de construção de uma estrutura de suporte para as almofadas das rendeiras de bilro da Associação das Artesãs de Saubara (Bahia), utilizando como referenciais a análise ergonômica do trabalho e o design participativo, com fortalecimento das ações da associação na sua dimensão econômica, social, cultural e política no processo de incubação.

\section{MATERIAIS E MÉTODOS}

\section{Caracterização da Associação das Artesãs de Saubara}

Localizada no Recôncavo Baiano, às margens da Baia de Todos os Santos, Saubara nome de origem indígena que significa "terra dos comedores de formiga". A renda de bilro e o trançado de ouricuri, artesanatos produzidos nessa comunidade tradicional da Bahia, são uma marca, passada de geração a geração [7].

Atualmente, a associação conta com cerca de 110 associadas, sendo reconhecida pela comunidade local como Casa das Rendeiras. O trabalho da Associação de Artesãs de Saubara baseia-se na preservação de aspectos culturais, como o uso de linha de algodão de cor branca, formato tradicional da renda, e trabalho solidário como princípio definido por todas as rendeiras. A confecção da renda se transformou num ofício que complementa o sustento das famílias, visto que a maioria dessas artesãs trabalha pela manhã como marisqueiras e, à tarde, na atividade da renda de bilro.

\section{Análise Ergonômica do Trabalho das Rendeiras de Bilro}

A avaliação ergonômica da atividade das rendeiras de bilro baseou-se nos princípios da análise ergonômica do trabalho (AET). Esta proposta avalia a adaptação das condições laborais ao trabalhador por meio de observação do ambiente trabalho, das atividades que são desenvolvidas pelo corpo e das dificuldades físicas e cognitivas que afetam diretamente a vida dos trabalhadores. Sendo assim, a AET depende da participação efetiva dos indivíduos avaliados que, através de suas interpretações sobre os problemas, identificam os pontos críticos que os cercam [6].

Primeiramente, a AET procura delimitar o problema específico com base na análise dos principais pontos críticos, buscando entender o problema para, assim, poder elaborar métodos de intervenção. Nesse sentido, AET centra seus objetivos e métodos em 
melhorias e modificações no ambiente de trabalho, propondo estratégias de prevenção de riscos, conforto, segurança e bem-estar ao trabalhador [10].

Segundo Fialho e Santos [1],

a AET comporta três fases: de análise da demanda, análise da tarefa e análise das atividades. A análise a demanda é a definição do problema a ser analisado, a partir de uma negociação com os diversos atores sociais envolvidos; a análise da tarefa é o que o trabalhador deve realizar e as condições ambientais, técnicas e organizacionais desta realização; a análise das atividades é o que o trabalho, efetivamente, para executar a tarefa. É a análise do comportamento do homem no trabalho. [1]

A partir da análise da demanda, foram levantadas as questões organizacionais das situações de trabalho em estudo através de entrevistas com as rendeiras de bilro e da matriz de priorização de problemas. Esta última técnica, elemento do diagnóstico rápido participativo, é uma ferramenta que permite o levantamento e a discussão dos principais problemas identificados durante o diagnóstico de acordo com sua importância e/ou urgência [11]. Na análise da tarefa, foram utilizadas observações aberta e armada (vídeos, fotografias) e o método RULA (Rapid Upper Limb Assessment), descrito por Mc Atamney e Corlett [3]. A análise das atividades foi feita através da utilização da técnica de autoimagem, por meio de vídeos e fotografias. Após a visualização das tarefas que executam, as trabalhadoras puderam perceber a sobrecarga a que seus corpos estão submetidos e, consequentemente, refletir sobre as possibilidades de mudança.

\section{Design Participativo}

Segundo Lima et al. [2], design social é aquele que vai além da satisfação das necessidades econômicas e mercadológicas para beneficiar toda a sociedade. Uma ampla agenda de pesquisa para o design participativo deve começar considerando uma série de questões. Pode-se usar uma abordagem multifacetada para explorar essas questões. Questionários de pesquisa e entrevistas com profissionais de serviços humanos, designers e administradores de agências podem ser conduzidos para reunir informações sobre percepções e atitudes, a fim de solicitar sugestões para mudança. A combinação de métodos de pesquisa deve explorar questões que variam do amplo contexto social, dentro do qual os designers trabalham, até especificidades para desenvolver um produto voltado para um sistema de clientes em particular [4].

Segundo Zanella et al. [12], a renda de bilro é uma manifestação cultural. Assim, deve ser entendida como atividade social realizada por um coletivo. Ao aprendê-la, o indivíduo toma parte não somente de um fazer, mas também de toda a história e valores que lhe são característicos, imprimindo-se uma marca singular. A observação participativa possibilita o ingresso de designers, ergonomistas e outros profissionais em ambientes sociais desse tipo, permitindo observar e documentar as necessidades sociais que podem ser atendidas pelo design participativo.

O processo de design participativo, desenvolvido neste estudo, teve como principal foco a adequação do posto de trabalho das rendeiras à atividade por elas desenvolvida. 


\section{RESULTADOS E DISCUSSÃO}

\section{Análise Ergonômica do Trabalho das Rendeiras de Bilro}

No processo de análise da demanda, as rendeiras de bilro da Associação das Artesãs de Saubara relataram que os principais problemas estruturais desta atividade laboral são: peso da almofada onde se faz a renda, falta de espaço para movimentar os membros inferiores e dificuldades para manter a coluna encostada sobre alguma superfície de apoio durante $o$ ato de rendar. De acordo com o relato das trabalhadoras, a almofada deve ser posicionada de forma paralela e perpendicular a elas, durante a ação de rendar, e este ato de carregar a almofada, para modificar o posicionamento, promove uma sobrecarga na musculatura do pescoço (músculos da região cervical da coluna vertebral). A falta de espaço para movimentar as pernas gera câimbras e formigamento (parestesia) em membros inferiores, enquanto a falta de apoio para a coluna vertebral leva ao aparecimento de dores na região lombar (lombalgias).

A análise da tarefa das rendeiras de bilros evidenciou condições posturais inadequadas, tais como: excessiva flexão do tronco (associado à falta de apoio para a coluna vertebral) e flexão dos braços (acima de 45 graus). Além disso, foi verificado que o peso da almofada demanda grandes esforços musculares do trapézio superior e do angular da escápula (Figura 1).

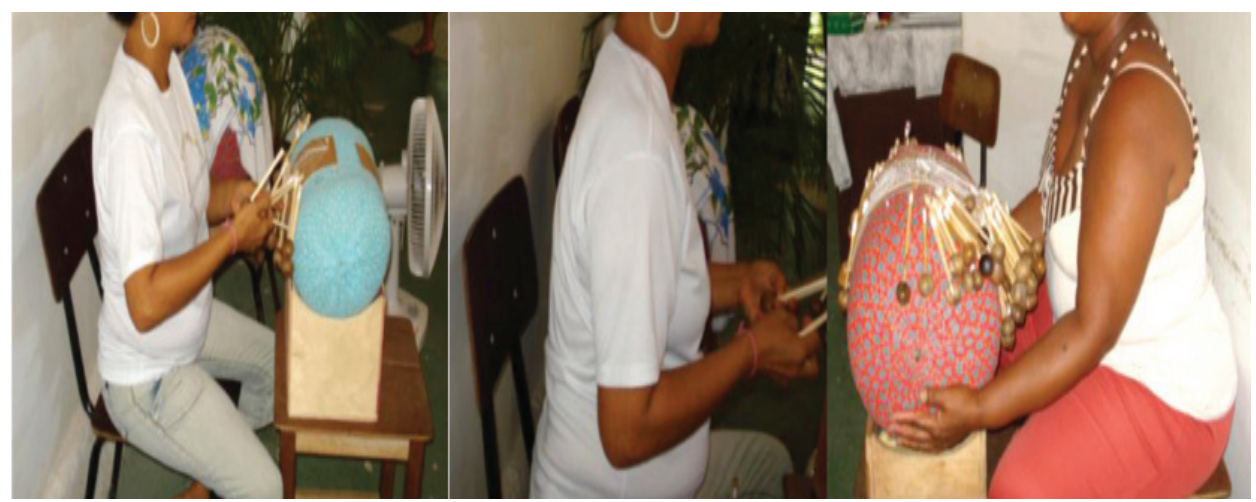

Esses aspectos relacionaram-se às queixas álgicas das rendeiras, localizadas sobretudo na coluna lombar e sobre os músculos da cintura escapular, principalmente, trapézio superior e angular da escápula. A tarefa das rendeiras obteve escore 6, no método RULA, sugerindo a necessidade de investigações e inserções de mudanças na estrutura física do ambiente de trabalho.

A análise das atividades feita através da utilização da técnica de autoimagem, com apoio de fotografias e vídeos, permitiu que as trabalhadoras refletissem sobre o posicionamento adotado durante a atividade laboral, concluindo que a estrutura de suporte para a almofada, caixote sobre banqueta, não contribui para a realização de um trabalho ergonomicamente adaptado.

A AET da atividade das rendeiras de bilro sugere a modificação da estrutura de
Figura 1 - Posturas adotadas pelas rendeiras de bilro da Associação das Artesãs de Saubara durante atividade laboral. 
suporte para a almofada, no intuito de garantir condições posturais adequadas tais como, coluna ereta e plenamente recostada, braços com ângulo de flexão menor que 45 graus e pernas com liberdade para deslocamento durante a atividade laboral.

\section{Desenvolvimento Participativo do Suporte para Almofada das Rendeiras de Bilro}

O primeiro movimento na construção do suporte para almofada das rendeiras foi informá-las sobre os principais objetivos deste processo, dentre eles, tornar o trabalho menos insalubre, diminuir os esforços físicos, prevenir doenças ocupacionais e, principalmente, desenvolver uma estrutura de acordo com as sugestões e necessidades apontadas pelas trabalhadoras.

Posteriormente, foi identificada a necessidade de construir um suporte que atendesse diferentes padrões antropométricos (altura corporal e comprimento dos membros inferiores) e as demandas das atividades laborais. Nesta perspectiva, foi elaborado um primeiro protótipo em madeira composto de um tampo com altura fixa, associado à pernas articuladas em " $X$ ", dotada de estruturas removíveis de suporte para almofada, formando uma única peça (Figura 2). Esse protótipo, composto por um sistema de travas, possibilita o uso de um novo modelo de almofada (Figura 2), mais leve, que permite o manuseio com menos esforço, e consequentemente, diminui a sobrecarga em membros superiores.

Esse protótipo elimina também a limitação de extensão do joelho, pois há espaço suficiente sob o tampo para a sua movimentação. Em contrapartida, as rendeiras apontaram algumas limitações para o protótipo, dentre elas: largura insuficiente para acomodação da coxa e perna de algumas rendeiras, falta de praticidade para regular a altura do suporte e, principalmente, dificuldade para trabalhar com o novo modelo de almofada. Este último aspecto relaciona-se com a cultura de confeccionar sua própria almofada de trabalho com materiais da própria região a partir de um conhecimento repassado entre gerações - tentar alterá-lo não foi a melhor estratégia.

Figura 2 - Primeiro protótipo do suporte para almofada das rendeiras de bilro da Associação das Artesãs de Saubara.

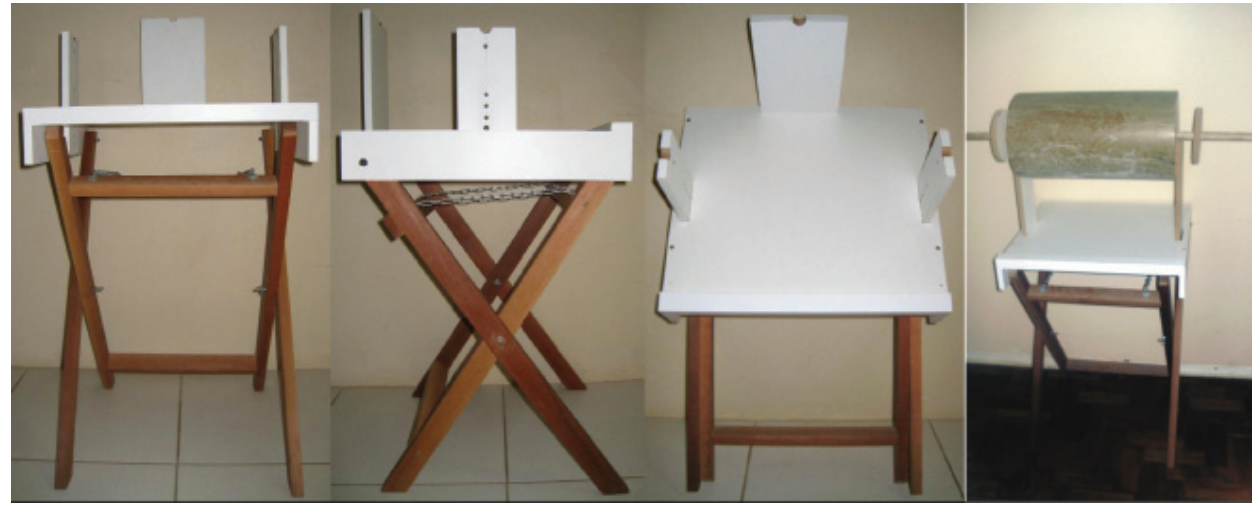

De acordo com as inadequações do primeiro protótipo, resolveu-se construir um segundo protótipo, em estrutura metálica, composto por três regulagens. Dentre essas, regulagem da altura do suporte, eixo para rotação do suporte, permitindo que a almofada fique orientada de forma paralela e perpendicular às rendeiras e eixo de inclinação permitindo 
que a almofada fique inclinada em diferentes ângulos. Além disso, o suporte para almofada deveria contemplar a liberdade para deslocamento dos membros inferiores durante a atividade laboral. A figura 3 representa o croqui do segundo protótipo. Este croqui foi apresentado às rendeiras de bilro que aprovaram a construção do segundo protótipo.

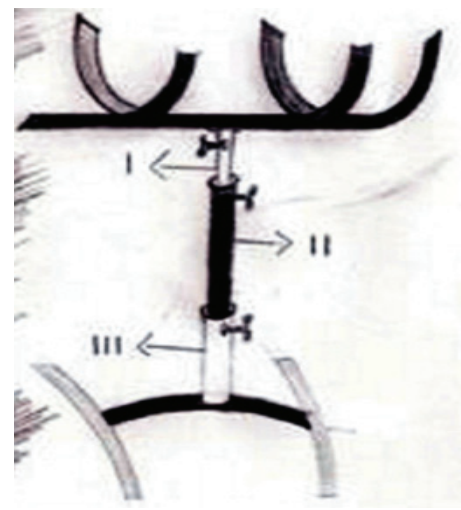

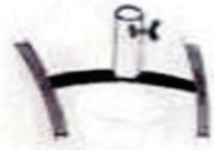

III
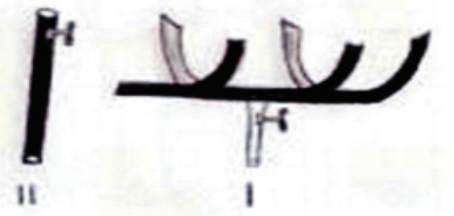

Figura 3 - Croqui do segundo protótipo para almofada das rendeiras. I - barra que permite a rotação do suporte; ॥ - barra que permite regular a altura do suporte; III - base do suporte.
Este segundo protótipo (Figura 4) foi apresentado às trabalhadoras, que solicitaram um último ajuste relacionado à configuração de sua base de sustentação.

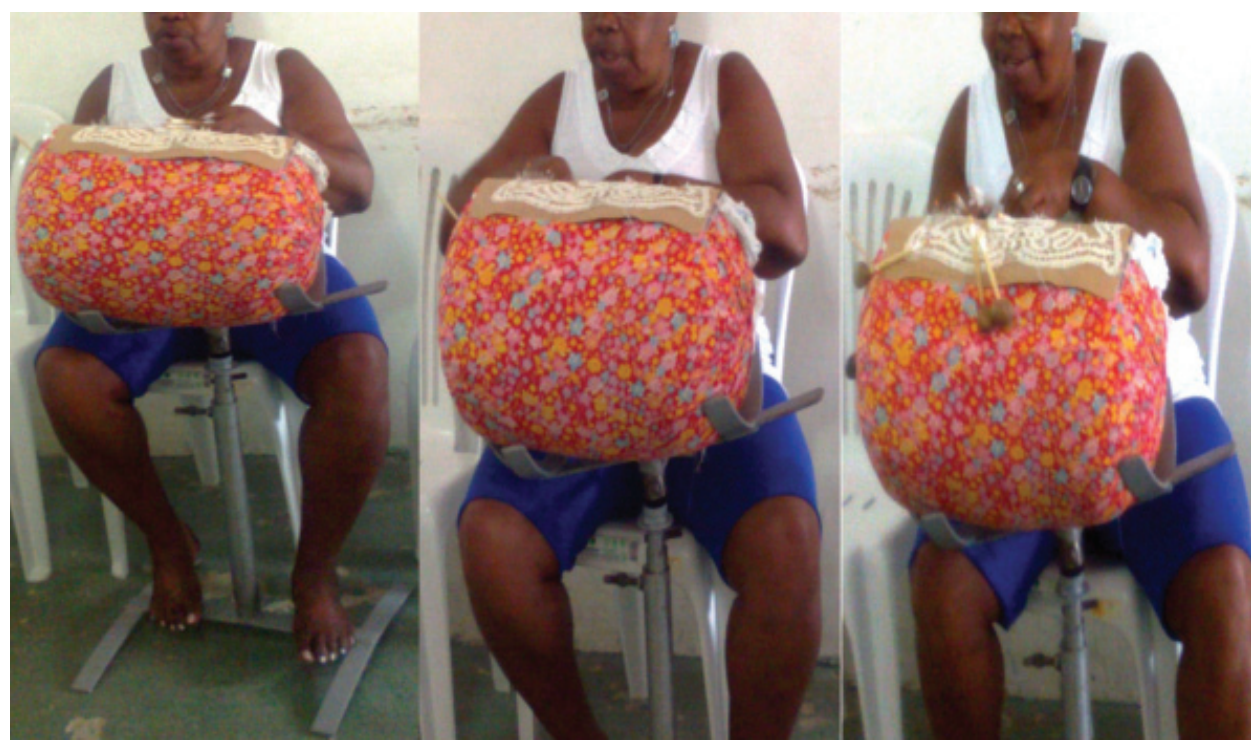

Segundo as rendeiras, o formato da base não permitiu que o suporte se aproximasse do corpo, sendo bloqueado pelos pés da cadeira onde as rendeiras ficam sentadas, o que continua sobrecarregando a coluna, em posição fletida. A adaptação proposta foi realizada (Figura 5) e esse novo protótipo serviu como base para construção de dez suportes, a um custo de 180 reais por unidade, valor referente ao serviço de serralheiro e aos materiais. Esses suportes serão utilizados pelo período de seis meses pelas rendeiras de bilro.
Figura 4 - Teste do segundo protótipo por uma rendeira de bilro da Associação das Artesãs de Saubara. 
Figura 5 - Segundo protótipo para almofada das rendeiras de bilro, com a discriminação das subpartes e suas respectivas medidas de referência utilizadas na construção do protótipo.

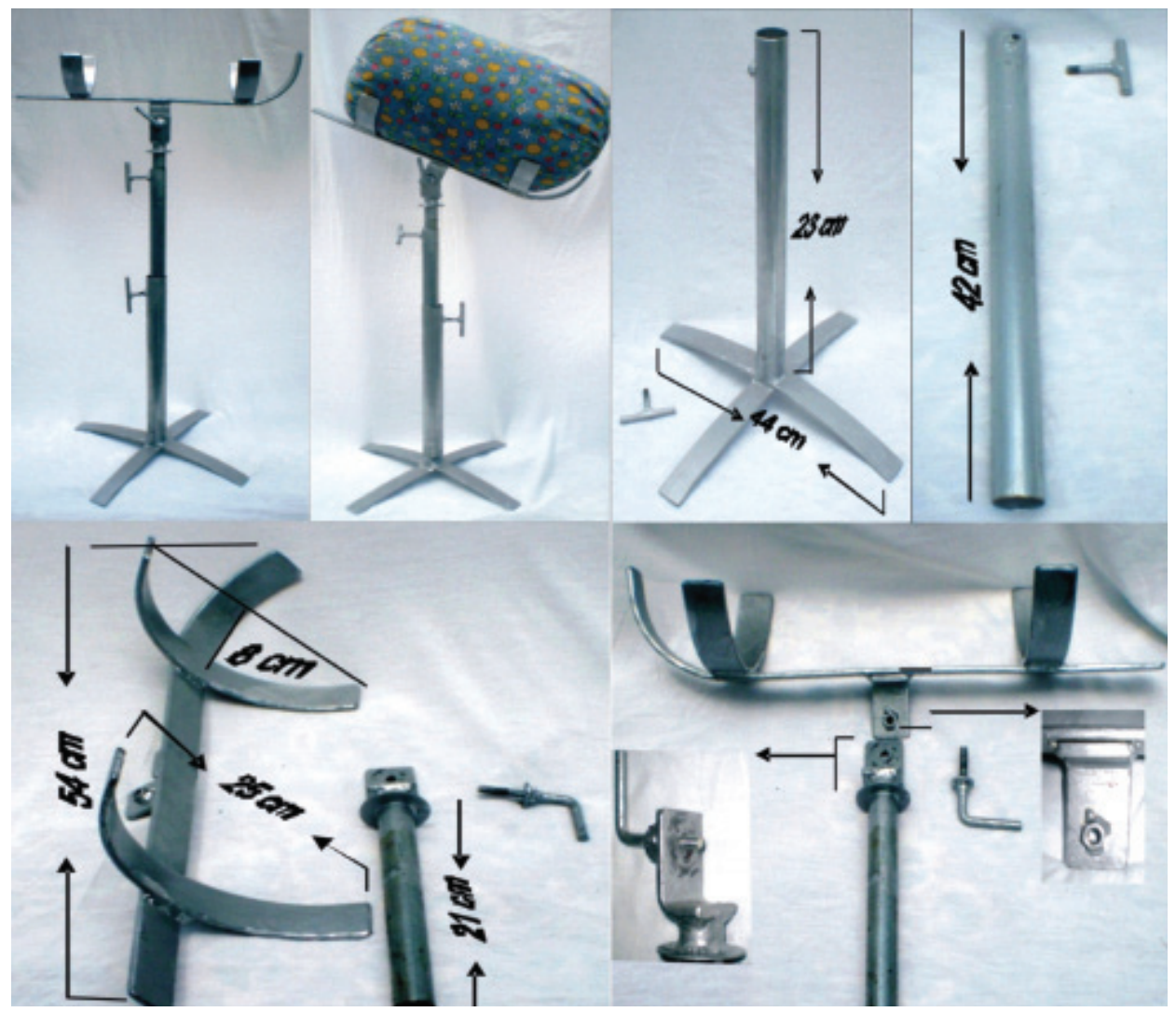

Esse período de utilização, de seis meses, permitirá que as trabalhadoras verifiquem a praticidade do uso do novo suporte para que novas unidades sejam construídas de acordo com a percepção de possíveis inadequações, que só poderão ser identificadas em médio ou longo prazo. Espera-se que possa melhorar a qualidade de vida das artesãs e que esta iniciativa possa ser replicada em outras regiões do Brasil. É importante considerar também que o processo da construção foi educativo tanto para as artesãs como para a equipe acadêmica, que trabalhou com a problematização da questão da saúde e da necessidade de cuidados preventivos voltados para a qualidade de vida, a partir da atividade de um empreendimento solidário formado por mulheres.

\section{REFERÊNCIAS}

[1] FIALHO, F. A. P.; SANTOS, N. Manual de Análise Ergonômica do Trabalho. 2. ed. Curitiba: Gênesis Editora, 1997.

[2] LIMA, M. V. M. et. al. A contribuição do design social para projetos de extensão universitária "papel social" e "revitalização histórica - cultural do bairro da Barra". Extensão em Foco, n. 4, p. 173-183, 2009.

[3] MC ATAMNEY, L.; CORLETT,E. N. RULA: a survey method for the investigation of work-related upper limb disorders. Applied Ergonomics, Volume 24, Issue 2, April 1993, Pages 91-99, http://dx.doi.org/10.1016/0003-6870(93)9008o-S. 
[4] MARGOLIN, V.; MARGOLIN, S. Um “modelo social” - Questões de prática e pesquisa. Design em foco, v. 1, n. 1, 2007.

[5] SALDANHA, M. C. W., et al. As razões do não adoecer: ocorrência de DORT em rendeiras de bilro. In: XVII ENCONTRO NACIONAL DE ENGENHARIA DE PRODUÇÃO, Foz do Iguaçu, 2007. Anais. Rio de Janeiro: Associação Brasileira de Engenharia de Produção, res. TR600450_9640.

[6] SALERNO, M. S. Análise ergonômica do trabalho e projeto organizacional: uma discussão comparada. Produção, v. 9, p. 45-60, 1999, http://dx.doi.org/10.1590/ So103-65131999000400003.

[7] SEBRAE. Artesanato da Bahia, 2009. Disponível em: <http://www.biblioteca. sebrae. com.br/bds/bds.nsf/79281B9AE499F4568325766Boo4CD $743 / \$ F i l e /$ NTooo42C66.pdf>. Acesso em: 16 dez. 2011.

[8] SILVA, R. M. A.; FARIA, M. S. Tecnologias sociais e economia solidária: diretrizes, desafios e perspectivas para políticas públicas. In: BOCAYUVA, P. C. C.; VARANDA, A. P. M. Tecnologia social, econômica solidária e políticas públicas. Rio de Janeiro: Fase, 2009. p. 71-91.

[9] SINGER, P. Economia solidária versus economia capitalista. Soc. estado, v.16, n.1-2, p. 100-112, 2001, http://dx.doi.org/10.1590/So102-69922001000100005.

[10] SOARES, M. M. Atualidades da ergonomia no Brasil e no mundo: uma visão geral. In: ENCONTRO NACIONAL DE ERGONOMIA DO AMBIENTE CONSTRUÍDO (ENEAC), n.1., 2007, Recife. Anais. Recife: Associação Brasileira de Ergonomia, 2007.

[11] VERDEJO, M. E. Diagnóstico rural participativo. Brasília: MDA/Secretaria da Agricultura Familiar, 2006.

[12] ZANELLA, A. V.; BALBINOTT, G.; PEREIRA, R. S. A renda que enrenda: Analisando o processo de constituir-se rendeira. Educação e Sociedade, v. 21, n. 71, p. 235-252, 2000, http://dx.doi.org/10.1590/So101-73302000000200011.

GABRIEL RIBEIRO professor assistente do Centro de Ciências Agrárias, Ambientais e Biológicas da Universidade Federal do Recôncavo da Bahia (UFRB) - e-mail:fta_gabrielribeiro@yahoo.com.br

TATIANA RIBEIRO VELLOSO doutora em Geografia pela Universidade Federal de Sergipe e professora assistente do Centro de Ciências Agrárias, Ambientais e Biológicas da Universidade Federal do Recôncavo da Bahia (UFRB) 